\title{
GAMBARAN KEJADIAN PERDARAHAN POSTPARTUM DI RUMAH SAKIT UMUM DAERAH PANGKEP
}

\author{
Nopiyanti \\ Akbid Aisyah Kabupaten Pangkep \\ Alamat Korespondensi: (Nopiyantiabbas@yahoo.com/085242161347)
}

\begin{abstract}
ABSTRAK
Penelitian ini adalah penelitian Deskriptif dengan desain penelitian yang menggunakan data sekunder dimana data diambil dari medical record, register PNC yang dimaksud untuk mengetahui Gambaran Kejadian Perdarahan Postpartum Di Rumah Sakit Umum Daerah Pangkep Tahun 2015. Cara pengambilan sampel yaitu dengan total sampling dengan jumlah sampel yang diperoleh sebanyak 40 responden. Hasil penelitian yang diperoleh yaitu ditinjau dari segi umur ada $<20$ dan $>$ 35 Tahun, yaitu sebanyak 11 responden $(27,5 \%)$ sedangkan umur 20 sampai 35 tahun sebanyak 29 responden $(72,5 \%)$. Dari segi paritas ada 37 responden $(92,5 \%)$ ibu dengan paritas $1-3$ tahun sedangkan paritas $\geq 4$ ada 3 responden $(7,5 \%)$. Untuk jarak kelahiran $\geq 2$ tahun terdapat 31 responden $(77,5 \%)$ sedangkan jarak kelahiran $<2$ tahun ada 9 responden $(22,5 \%)$.
\end{abstract}

\section{Kata Kunci : Perdarahan, Postpartum}

\section{PENDAHULUAN}

Perdarahan postpartum atau perdarahan pasca persalinan adalah salah satu penyebab kematian ibu melahirkan. Lima faktor utama penyebab kematian ibu melahirkan adalah perdarahan postpartum atau perdarahan pasca persalinan, hipertensi dan infeksi. Menurut WHO, perdarahan menempati presentase tertinggi penyebab kematian ibu (28\%), dimana pada tahun 2011 tercatat $81 \%$ diakibatkan karena komplikasi selama kehamilan, persalinan dan nifas, sebagian besar dari kematian ibu disebabkan karena perdarahan, infeksi dan preeklampsia. Dari angka tersebut, diperoleh gambaran etiologi antara lain: atonia uteri $(50 \%-60 \%)$, sisa plasenta $(23 \%-24 \%)$, retensio plasenta $(16 \%-$ $17 \%)$, laserasi jalan lahir (4\%-5\%) dan kelainan darah $(0,5 \%-0,8 \%)$ (Vinalupfia, 2011).

Berdasarkan data yang diperoleh dari Dinas Kesehatan Provinsi Sulawesi Selatan tahun 2010, jumlah kematian ibu tercatat 121/100.000 kelahiran hidup. Penyebab kematian tertinggi adalah disebabkan oleh perdarahan sebesar 63 responden $(52,06 \%)$, eklampsia sebesar 28 responden $(23,14 \%)$, infeksi sebesar 2 responden $(1,65 \%)$, abortus sebesar 1 responden $(0,82 \%)$, partus lama sebesar 1 responden $(0,82 \%)$ dan lain - lain sebesar 26 responden $(21,48 \%)$. Pada tahun 2011, jumlah kematian ibu yaitu 116/100.000 kelahiran hidup, yang disebabkan oleh perdarahan 55 responden $(47,41 \%)$, eklampsia 25 responden $(21,55 \%)$, infeksi 2 responden $(1,72 \%)$, abortus 3 responden $(2,58 \%)$ dan lain-lain 31 responden $(26,72 \%)$
(Sulfianasiraj, 2014). Adapun jumlah kematian ibu yang dilaporkan pada tahun 2012 yaitu 160 responden atau 110,26/100.000 kelahiran hidup, terdiri dari kematian ibu hamil 45 responden atau $(28,1 \%)$, kematian ibu bersalin 60 responden $(40 \%)$, kematian ibu nifas 55 responden (30\%). Adapun kematian ibu menurut umur yaitu $<20$ tahun sebanyak 12 responden, umur 20-34 tahun sebanyak 102 responden, dan $\geq 35$ tahun sebanyak 46 responden. Sedangkan pada tahun 2014 tercatat jumlah kematian ibu sebesar 116 responden, penyebab terbanyak adalah perdarahan sebesar 72 responden $(62,06 \%)$, preeklampsia 19 responden $(16,37 \%)$, infeksi 5 responden $(4,31 \%)$.

Pada tahun 2014 jumlah kematian ibu (AKI) karena perdarahan postpartum di Kabupaten Pangkep sebanyak 0,88/1000 kelahiran hidup, dan pada tahun 2015 meningkat menjadi 1,6/1000 kelahiran hidup. Sedangkan kejadian perdarahan postpartum di Rumah Sakit Umum Daerah Pangkep pada tahun 2014 berjumlah 13 responden dari 629 persalinan sedangkan pada tahun 2015 berjumlah 40 responden dari 610 persalinan.

\section{BAHAN DAN METODE}

Lokasi, populasi, dan sampel

Penelitian deskriptif adalah penelitian yang bertujuan untuk menjelaskan atau mendeskripsikan suatu keadaan, peristiwa, objek apakah responden, atau segala sesuatu yang terkait dengan variabel-variabel yang bisa dijelaskan baik dengan angka-angka maupun kata-kata yang ada, tanpa dilebihlebihkan, Penelitian deskriptif dalam hal ini 
yaitu untuk mendapatkan gambaran kejadian perdarahan postpartum di RSUD Pangkep Tahun 2015. Populasi dalam penelitian ini adalah semua ibu yang pernah melahirkan diruangan bersalin RSUD Pangkep dengan jumlah 610 responden dari Januari-Desember 2015 dan Sampel diambil berdasarkan kualitas dan karakteristik suatu populasi akan menyebabkan suatu penelitian menjadi bias, tidak dapat dipercaya dan besarnya sampel dalam penelitian ini diperoleh secara total sampling yaitu keseluruhan ibu yang mengalami perdarahan postpartum sebanyak 40 responden.

Pengolahan Data

1. Editing

Hasil wawancara, angket, atau pengamatan dari lapangan harus dilakukan penyuntingan (editing) terlebih dahulu. Secara umum editing adalah merupakan kegiatan untuk pengecekan dan perbaikan isian formulir atau kuesioner tersebut :

2. Coding

Setelah semua kuesioner diedit atau disunting, selanjutnya dilakukan peng"kodean"atau "coding", yakni mengubah data berbentuk kalimat atau huruf menjadi data angka atau bilangan. Koding atau pemberian kode ini sangat berguna dalam memasukkan data (data

3. Tabulasi Data

Setelah dilakukan kegiatan editing dan koding dilanjutkan dengan mengelompokkan data kedalam suatu tabel menurut sifat-sifat yang dimiliki sesuai dengan tujuan penelitian.

\section{Analisis Data}

Anlisa univariat dilakukan terhadap tiap variabel dari hasil penelitian ini berupa distribusi dan presentase pada setiap variabel yaitu meliputi motivasi lansia datang ke posyandu lansia, dan frekuensi kunjugan ke posyandu lansia.

\section{HASIL PENELITIAN}

1. Deskriptif Kejadian Perdarahan Postpartum Berdasarkan Umur

Tabel 1. Distribusi Kejadian Perdarahan Postpartum Berdasarkan Umur di RSUD Pangkep Tahun 2015.

\begin{tabular}{|c|c|c|}
\hline Umur & Frekuensi & $\%$ \\
\hline $\begin{array}{c}\text { Risiko Rendah } \\
(20-35)\end{array}$ & 29 & 72,5 \\
$\begin{array}{c}\text { Risiko Tinggi } \\
(<20 \text { dan }>35)\end{array}$ & 11 & 27,5 \\
\hline Jumlah & 40 & 100 \\
\hline
\end{tabular}

Berdasarkan tabel 1. diperoleh informasi bahwa dari 40 responden yang mengalami perdarahan postpartum di dapatkan pada risiko tinggi ( $<20$ dan $>35$ Tahun) yaitu sebanyak 11 responden $(27,5 \%)$, sedangkan risiko rendah yaitu umur 20 sampai 35 tahun sebanyak 29 responden (72,5\%).

2. Deskriptif Kejadian Perdarahan Postpartum Berdasarkan Paritas

Tabel 2. Distribusi Kejadian Perdarahan Postpartum Berdasarkan Paritas di RSUD Pangkep Tahun 2015.

\begin{tabular}{|c|c|c|}
\hline Paritas & $\mathrm{n}$ & $\%$ \\
\hline $\begin{array}{c}\text { Risiko Rendah } \\
(1-3)\end{array}$ & 37 & 92,5 \\
$\begin{array}{c}\text { Risiko Tinggi } \\
(\geq 4)\end{array}$ & 3 & 7,5 \\
\hline Jumlah & 40 & 100 \\
\hline
\end{tabular}

Dari tabel 2. diperoleh informasi bahwa dari 40 responden yang mengalami perdarahan postpartum di dapatkan pada risiko rendah (1-3) yaitu sebanyak 37 responden $(92,5 \%)$, sedangkan risiko tinggi ( $\geq 4$ ) yaitu 3 responden $(7,5 \%)$.

3. Deskriptif Kejadian Perdarahan Postpartum Berdasarkan Jarak Kelahiran

Tabel 3. Distribusi Kejadian Perdarahan Postpartum berdasarkan Jarak Kelahiran di Rumah Sakit Umum Daerah Pangkep Tahun 2015.

\begin{tabular}{|c|c|c|}
\hline Jarak Kelahiran & Frekuensi & $\%$ \\
\hline $\begin{array}{c}\text { Risiko Rendah } \\
(\geq 2 \text { tahun) } \\
\begin{array}{c}\text { Risiko Tinggi } \\
(<2 \text { tahun) }\end{array}\end{array}$ & 31 & 77,5 \\
\hline Jumlah & 40 & 22,5 \\
\hline
\end{tabular}

Dari tabel 3 diperoleh informasi bahwa ibu yang mengalami perdarahan postpartum di RSUD Pangkep adalah 40 responden $(6,5 \%)$, sedangkan jumlah ibu bersalin yang tidak mengalami perdarahan postpartum adalah 570 responden (93,5\%).

\section{PEMBAHASAN}

Setelah dilakukan penelitian dengan melalui pengolahan dan penyajian data beserta hasilnya di RSUD Pangkep tahun 2015, maka dilakukan pembahasan hasil penelitian sesuai dengan variabel yang diteliti.

1. Kejadian Perdarahan Postpartum

Berdasarkan Umur

Ditinjau dari umur diperoleh data bahwa dari 40 kasus perdarahan postpartum terdapat 29 kasus (72,5\%) pada ibu bersalin dengan umur 20-35 
tahun dan 11 kasus $(27,5 \%)$ pada ibu bersalin dengan umur $<20$ dan $>35$ tahun.

Umur menjadi faktor predisposisi terjadinya perdarahan postpartum karena pada wanita hamil dan melahirkan pada usia dibawah 20 tahun ternyata 2 sampai 5 kali lebih tinggi terjadi perdarahan postpartum yang terjadi pada usia 20 sampai 29 tahun dan meningkat lagi sesudah usia 30 sampai 35 tahun, umumnya berkaitan dengan belum matangnya alat-alat reproduksi wanita untuk hamil jika < dari 20 tatun, sedangkan $>35$ tahun akan mengalami penurunan dalam hal kesuburan, dan proses fungsi tubuhnya sudah mengalami kemunduran sehingga fungsi organ-organ reproduksinya sudah mulai berkurang. Berdasarkan data yang diperoleh menunjukkan bahwa pada umur 20-35 menjadi jumlah tertinggi karena umur 20-35 tahun adalah masa usia produktif yang baik untuk hamil sehingga banyak ibu hamil yang melahirkan pada usia 20 sampai 35 tahun, baik yang melahirkan secara normal maupun diikuti dengan komplikasi. Sedangkan pada umur $<20$ tahun, banyak ibu hamil yang belum siap untuk hamil, baik belum siap secara fisik maupun secara psikologi. Umur > 35 tahun banyak ibu yang sudah menghentikan kehamilannya karena, selain faktor usia lanjut juga ibu dengan usia ini tidak mampu untuk melahirkan dan merawat bayinya.

2. Gambaran Kejadian Perdarahan Postpartum Berdasarkan Paritas

Ditinjau dari paritas ibu diperoleh data bahwa dari 40 kasus perdarahan postpartum terdapat 37 kasus $(92,5 \%)$ dengan paritas $1-3$, dan 3 kasus $(7,5 \%)$ pada ibu bersalin dengan paritas $\geq 4$. Dari data tersebut terlihat kejadian perdarahan postpartum tertinggi ada pada kelompok paritas risiko rendah (1-3) yaitu sebanyak 37 kasus $(92,5 \%)$,

Paritas menjadi faktor predisposisi perdarahan postpartum karena paritas $\geq 4$ menyebabkan reproduksi ibu bersalin yang mengalami penurunan karena seringnya hamil atau melahirkan menyebabkan parut pada dinding uterus, jika plasenta melekat pada bekas parut maka plasenta akan berimplantasi dengan sangat kuat, sehingga kemungkinan akan terjadi retensio plasenta. Namun dalam hasil penelitian menunjukkan bahwa pada kelompok paritas risiko rendah (1-3) mempunyai angka kejadian lebih tinggi karna, dengan banyaknya penyuluhan tentang program keluarga berencana baik yang diprogramkan oleh pemerintah setempat maupun instansi kesehatan bekerja sama dengan Dinas Kesehatan serta kegiatan-kegiatan yang dilakukan oleh organisasi-organisasi kemahasiswaan salah satunya seperti pembinaan kepada generasi muda, terutama dalam program Generasi berencana (Gen-Re), tidak menutup kemungkinan kesuksesan program KB ini terlihat yang menyebabkan banyak ibu hamil yang mengikiti program tersebut dengan memiliki 2 anak cukup. Sedangkan paritas $(\geq 4)$ menjadi kelompok jumlah yang rendah karna banyak ibu hamil yang menghentikan kehamilan karna mengingat risiko yang akan terjadi jika memiliki jumlah anak yang banyak seperti salah satunya terjadi perdarahan.

3. Gambaran Kejadian Perdarahan Postpartum Berdasarkan Jarak Kelahiran Ditinjau dari jarak kelahiran diperoleh data dari 40 kasus perdarahan postpartum terdapat 31 kasus $(77,5 \%)$ dengan jarak kelahiran $\geq 2$ tahun dan 9 kasus $(22,5 \%)$ pada ibu bersalin dengan jarak kelahiran $<2$ tahun. Dari data tersebut terlihat bahwa kejadian perdarahan postpartum tertinggi pada kelompok jarak kelahiran risiko rendah ( $\geq 2$ tahun) yaitu sebanyak 31 kasus $(77,5 \%)$.

Hasil penelitian menunjukkan bahwa pada kelompok jarak kelahiran risiko rendah ( $\geq 2$ tahun) menjadi jumlah yang lebih tinggi, berdasarkan data yang diperoleh sesuai dengan teori Moir dan Meyerscough (1972) yang dikutip Suryani (2008) yang mengatakan bahwa jarak antar kelahiran sebagai penyebab perdarahan postpartum karena persalinan yang berturut-turut dalam jangka waktu yang singkat akan mengakibatkan kontraksi uterus menjadi kurang baik, karena rahim dan kesehatan ibu belum pulih dengan baik uterus menjadi kurang baik, karena rahim dan kesehatan ibu belum pulih dengan baik. $\begin{array}{lll}\text { Gambaran Kejadian } & \text { Perdarahan } \\ \text { Postpartum } & \end{array}$

Setelah dilakukan penelitian didapatkan jumlah ibu yang bersalin di Rumah Sakit Umum Daerah Pangkep Tahun 2015 adalah 610 responden (100\%), ibu yang mengalami perdarahan postpartum sebanyak 40 responden $(6,5 \%)$ dan jumlah ibu yang tidak mengalami perdarahan postpartum adalah 570 responden (93,5\%). Dari data ini kita dapat mengetahui bahwa jumlah kejadian perdarahan postpartum khususnya di RSUD Pangkep masih rendah yaitu 40 responden yang mengalami perdarahan postpartum dari 
610 persalinan, berarti ada 570 responden yang bersalin dan tidak mengalami komplikasi perdarahan post partum, karena dengan banyaknya pelatihan-pelatihan dan seminar-seminar bagi para tenaga kesehatan khususnya para bidan tentang skill dalam menangani kegawatdaruratan yang terbaru seperti salah satunya untuk menangani perdarahan postpartum, serta sejak dini diberikan konseling kepada para remaja dan ibu hamil dengan kehamilan muda tentang tanda bahaya kehamilan khususnya penyebab perdarahan postpartum sehingga tidak menutup kemungkinan kesuksesan pelatihan dan konseling yang diberikan mampu menekan angka kejadian perdarahan postpartum di RSUD Pangkep.

\section{KESIMPULAN}

1. Jumlah kejadian perdarahan postpartum yaitu sebanyak 40 responden $(6,5 \%)$ dari 610 responden $(100 \%)$ ibu yang bersalin.

2. Berdasarkan umur, jumlah tertinggi ada pada risiko rendah ( 20-35 tahun) yaitu sebanyak 29 responden $(72,5 \%)$ dan jumlah terendah ada pada risiko tinggi $(<20$
- >35 tahun) yaitu sebanyak 11 responden $(27,5 \%)$.

3. Berdasarkan paritas, jumlah tertinggi ada pada risiko rendah (1-3) yaitu sebanyak 37 responden $(92,5 \%)$ dan jumlah terendah ada pada risiko tinggi $(\geq 4)$ yaitu 3 responden $(7,5 \%)$.

4. Berdasarkan jarak kehamilan, jumlah tertinggi ada pada risiko rendah $(\geq 2$ tahun) yaitu 31 responden $(77,5 \%)$ dan jumlah terendah ada pada risiko tinggi $(<2$ tahun) yaitu 9 responden $(22,5 \%)$.

\section{SARAN}

1. Bagi Institusi Pendidikan Diharapkan bagi institusi mempertimbangkan untuk penyuluhan di masyarakat.

2. Bagi Tempat Penelitian

Meningkatkan dalam pemberian pelayanan yang terbaik bagi pasien sesuai dengan prosedur yang telah ditetapkan.

3. Bagi Peneliti

Lebih meningkatkan membaca buku buku, artikel, jurnal, dan majalah majalah tentang perdarahan postpartum.

\section{DAFTAR PUSTAKA}

Diyah Fitriyani. 2015. Populasi Dan Sampel Dalam Penelitian Kuantitatif.

http://diyahfitriyani94.blogspot.co.id/2015/05/populasi-dan-sampel-dalam-penelitian.html. 10 Mei 2016 (21.00).

Nur Fatimah. 2013. GambaranKebiasaanMembacaDikalangan

Mahasiswa.http://nurfatimahdaulay18.blogspot.co.id/,diaksestanggal 10 Mei 2016.

RestiUmaya. 2014. BeberapaFaktor Yang MempengaruhiPerdarahan Postpartum Primer. http://documents.tips/documents/bab-ii-tinjauan-pustaka- 55f5f4114288e.html

Sari, P.E., dan K.D. Rimandini. 2014 AsuhanKebidananMasaNifas (Postnatal Care). CetakanPertama. Trans Info Media. Jakarta.

Sumarni, 2013. KelainandanKomplikasidalamKehamilan. Maros

Suryamin. 2013. SurveiDemografi Dan Kesehatan Indonesia 2012.

http://Chnrl.org/pelatihan-demografi/SDKI- 2012.pdf. 20 Mei 2016 (16.00).

Suryana. 2012. Data Dan Jenis Data Penelitian

http://csuryana.wordpress.com/2010/03/25/data-dan-jenis-data-penelitian/. 28 April 2016 (20.00)

Vinalufia. 2011. AsuhanKebidananibuDenganPerdarahan Primer.

http://digilib.unimus.ac.id/files/disk1/150/itptunimus-gdl-vinalupfia-7480-1-1babipe-n.pdf. $22 \quad$ April 2016 (14.00). 